\title{
Contribution of mixing in the ABL to new particle formation based on observations
}

\author{
J. Lauros ${ }^{1,2}$, E. D. Nilsson ${ }^{2}$, M. Dal Maso ${ }^{1}$, and M. Kulmala ${ }^{1}$ \\ ${ }^{1}$ Division of Atmospheric Sciences, Department of Physical Sciences, P.O. Box 64, 00014 University of Helsinki, Finland \\ ${ }^{2}$ Department of Applied Environmental Science, Stockholm University, 10691 Stockholm, Sweden
}

Received: 5 April 2007 - Published in Atmos. Chem. Phys. Discuss.: 30 May 2007

Revised: 29 August 2007 - Accepted: 14 September 2007 - Published: 20 September 2007

\begin{abstract}
The connection between new particle formation and micro- and mesoscale meteorology was studied based on measurements at SMEAR II station in Southern Finland. We analyzed turbulent conditions described by sodar measurements and utilized these combined with surface layer measurements and a simple model to estimate the upper boundary layer conditions. Turbulence was significantly stronger on particle formation days and the organic vapor saturation ratio increase due to large eddies was stronger on event than nonevent days. We examined which variables could be the best indicators of new particle formation and concluded that the formation probability depended on the condensation sink and temporal temperature change at the top of the atmospheric boundary layer. Humidity and heat flux may also be good indicators for particle formation.
\end{abstract}

\section{Introduction}

Atmospheric aerosol formation consists of a complicated set of processes that include the production of nanometer-size clusters from gaseous vapors, the growth of these clusters to detectable sizes, and their simultaneous removal by coagulation with the preexisting aerosol particle population (e.g. Kerminen et al., 2001; Kulmala, 2003). While aerosol formation has been observed to take place almost everywhere in the atmosphere (Kulmala et al., 2004c), serious gaps in our knowledge regarding this phenomenon still exist. The first step of aerosol formation is nucleation, i.e. the formation of stable nanosize clusters. What makes these freshly-nucleated clusters to grow is one of the most interesting questions to date. It is believed that condensation of organic vapor in tandem with sulfuric acid leads to particle growth to detectable size (Kulmala et al., 2004a; Kulmala et al., 2004b; Hirsikko

Correspondence to: J. Lauros

(johanna.lauros@helsinki.fi) et al., 2005). However, the growth seems to happen only under specific conditions and it appears likely that some kind of activation is needed before the growth can start (Kulmala et al., 2006).

Several studies have been carried out to find out which atmospheric conditions favor new particle formation. Buzorius et al. (2003) studied boundary layer conditions and concluded that the probability of observing a new particle formation event depended on mean meteorological conditions such as mean values, variances and covariances of temperature, humidity and heat flux. Studies by Nilsson et al. (2001a) and Nilsson et al. (2006) showed that observations of particle formation were connected to cold-air outbreaks and suggested a link to meso- and microscale meteorology, as cold advection favors organized convection and secondary circulation.

Conditions in the atmosphere vary in short timescale and distance especially in the convective atmospheric boundary layer (ABL) and thereby meso- or microscale meteorology may be even more crucial to new particle formation than mean conditions. Theoretical studies (e.g. Easter and Peters, 1994; Kerminen and Wexler, 1995; Nilsson and Kulmala, 1998; Khosrawi and Konopka, 2003; Lauros et al., 2006) have shown that micro- and mesoscale variation and mixing may lead to or boost nucleation significantly in the atmosphere. In addition, Nilsson et al. (2001b) have shown that the observed particle formation events are connected to the onset of turbulent mixing. Ascending motion in large eddies may produce favorable ambient conditions for new particle formation at vapor concentrations that would not be enough in a stratified air mass. In thermic convection, well-known by glider pilots, vertical velocity may be up to several meters per second, which leads to an effective temperature decrease by adiabatic expansion and thereby increases saturation in an air parcel.

In a recent theoretical study, Anttila et al. (2004) suggested that large eddies may trigger activation of nucleated clusters. They introduced a simplified theoretical entrance

Published by Copernicus Publications on behalf of the European Geosciences Union. 

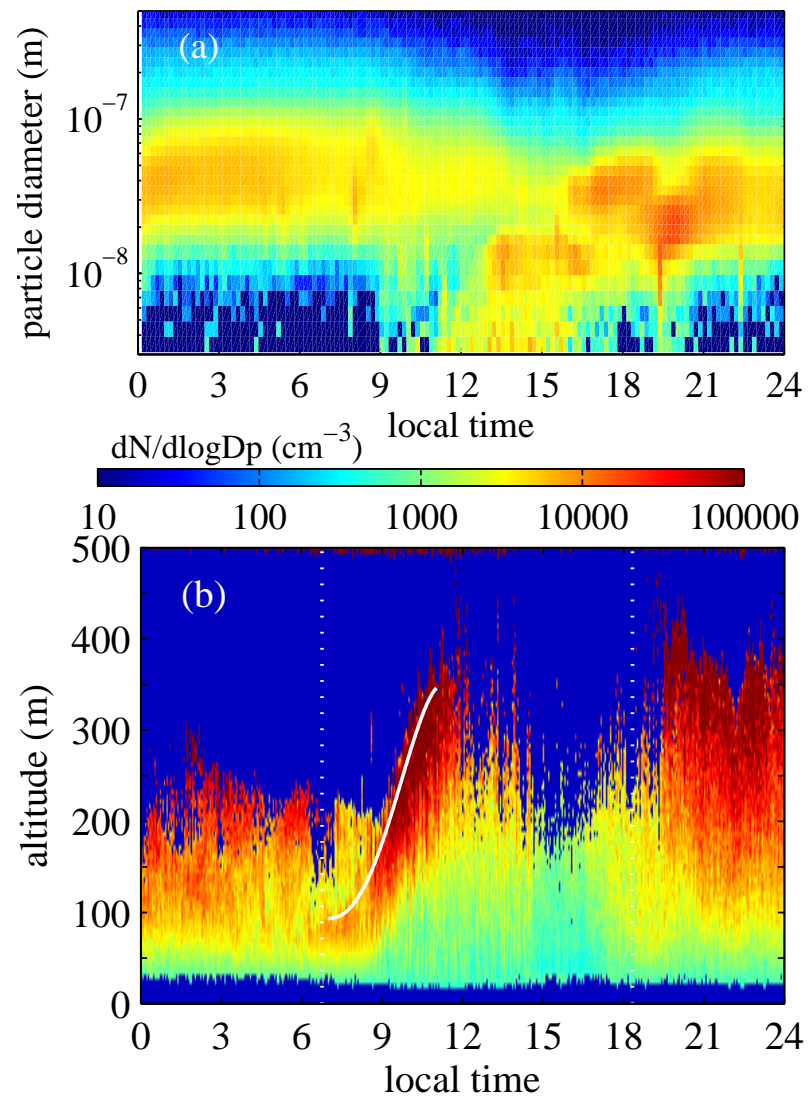

Fig. 1. (a) Observed new particle formation event in Hyytiälä 14 March 2003. The colors indicate particle concentration. (b) Mixing height can be defined as the maximum of sodar echo. The dotted vertical lines show sunrise and sunset time and the superimposed solid curve is the estimated mixed layer height.

to the problem in the form of an expression of the rate of change of the saturation ratio for organic compounds as a function of chemistry and temperature. In the current paper we have tested if observed mixing affect significantly on particle formation and utilized various observations carried out at the Finnish measurement station SMEAR II in Hyytiälä (see e.g. Kulmala et al., 2001b). In the ABL an air parcel goes through changes which cannot be described using solely surface measurements. The surface conditions do not predict particle formation in all cases when it could be possible at more favorable conditions at elevated altitudes (discussed in Sect. 4.2). Therefore we utilized sodar (SOund Doppler Acoustic Radar) observations. The effect of vertical flow (large eddies) on the saturation ratio of organic vapor $S_{o s}$ was studied and conditions at elevated heights in the ABL between days with a new particle formation event (see Fig. 1a) and nonevent days were compared (Sects. 4.1 and 4.3). The main aim of this paper is to exhibit how boundary layer meteorology will affect particle formation particularly via changing the saturation ratio of organic vapors.

\section{Saturation ratio of an organic vapor}

The time evolution of the saturation ratio of a vapor, $S=e / e_{\text {sat }}$, depends on sources, sinks and meteorological conditions. The sources and sinks (condensation on preexisting particles and transformation of substances through chemical reactions) affect the vapor pressure $e$ or the amount of vapor in the atmosphere, while the saturation vapor pressure $e_{\mathrm{sat}}$ depends on temperature $T$. The change of saturation ratio of a water-soluble organic vapor $S_{o s}$ can be derived from a reformation of the Clausius-Clapeyron equation (Anttila et al., 2004):

$$
\frac{d S_{o s}}{d t}=\frac{Q}{C_{0}}-S_{o s}\left(\frac{\Delta H_{o s}}{R T^{2}} \frac{d T}{d t}+C S\right) .
$$

Here $R$ is the universal gas constant and $\Delta H$ is the enthalpy of vaporization for a given organic compound. In this study $\Delta H_{o s}=170 \mathrm{~kJ} \mathrm{~mol}^{-1}$ which is a reasonable value for monoand dicarboxylic acids (see e.g. Strader et al., 1999). $C_{0}$ is the saturation vapor concentration of the organic vapor as a pure compound. The effect of the condensation sink CS on the saturation ratio is always negative $\left(d S_{o s} / d t \leq 0\right)$ while vertical motion and hence temperature change $\left(P_{\mathrm{met}}=-\frac{\Delta H_{o s}}{R T^{2}} \frac{d T}{d t}\right)$ may increase or decrease the saturation ratio, depending on the sign of $d T / d t$. If no significant sources exist $(Q=0)$, the integration of Eq. (1) gives

$$
\begin{aligned}
S_{O S}(t) & =S_{o s, 0} \exp \left\{-\int_{t_{1}}^{t_{2}}\left(\frac{\Delta H_{O S}}{R T^{2}} \frac{d T}{d t}+C S\right) d t\right\} \\
& =S_{O s, 0} \exp \left\{\frac{\Delta H_{O S}}{R}\left(\frac{1}{T_{2}}-\frac{1}{T_{1}}\right)-\frac{C S}{w}\left(z_{2}-z_{1}\right)\right\} .
\end{aligned}
$$

Here we have used the relationship $w=\partial z / \partial t$ and assumed that the vertical velocity $w$ is constant in the integrated layer.

We have studied relatively short temporal and spatial scales and assumed that diabatic heating (e.g. all radiation and changes of phase) can be ignored when the temperature of an air parcel is estimated. In this case the temperature change $d T / d t$ is a product of $w$ and the temperature dry adiabatic lapse rate, $\partial T / \partial z=\Gamma \approx-9.8 \mathrm{~K} \mathrm{~km}^{-1}$. If the temperature of an air parcel is known at any level $z_{1}(\mathrm{~m})$, it can be derived for another altitude $z_{2}$ as $T_{2}=T_{1}+\Gamma\left(z_{2}-z_{1}\right)$.

We have assumed that no sources (and chemical sinks) exist. Sources would lead to higher $d S_{o s} / d t$ and for this reason our results will more likely underestimate than overestimate the saturation ratio $S_{o s}$. Equation (3) shows that the effect of condensation sink depends on the strength of vertical velocity, while the first term depends only on the path of the air parcel and not on how fast it rises or descends.

\section{Material and methods}

The data consists of meteorological observations of 100 days during March-October 2003 and 2004, covering 18 nonevent and 82 event days. The classification to event and nonevent 
Table 1. The measurements (measurement altitude) and corresponding symbols used in this study.

\begin{tabular}{ll}
\hline sodar (Hyytiälä) & \\
\hline wind velocity $(50-500 \mathrm{~m})$ & $w$ \\
echo strength/mixing height $(50-500 \mathrm{~m})$ & $z_{i}$ \\
mast and tower (Hyytiälä) & $\bar{\theta}$ \\
temperature $(67.7 \mathrm{~m})$ & $\bar{q}$ \\
humidity $(67.7 \mathrm{~m})$ & $\overline{w^{\prime} \theta^{\prime}}$ \\
heat flux $(23.3 \mathrm{~m})$ & \\
\hline DMPS (Hyytiälä) & $\left(d N / d \log D_{p}\right)_{s}$ \\
\hline particle number size distributions 3-10 nm $(2 \mathrm{~m})$ & $\left(d N / d \log D_{p}\right)_{s}$ \\
particle number size distributions $10-500 \mathrm{~nm}(2 \mathrm{~m})$ & $d \bar{\theta} / d z=\gamma$ \\
\hline soundings (Tikkakoski) & \\
\hline temperature profile $(0-500 \mathrm{~m})$ & \\
\hline
\end{tabular}

days was based on visual analysis of particle data and following criteria for event days were used: a new mode had to start growing from nucleation mode size range and the mode had to grow and exist hours (Dal Maso et al., 2005).

The time periods cover 490 days altogether but we were able to observe the boundary layer growth in sodar data only on 100 days. The growing mixed layer reached an almost stationary height of 500-2500 m during afternoon. At this stage much of the boundary layer was out of range for our sodar, but we were primarily interested in the transient stage as this is typically when nucleation occurs (Nilsson et al., 2001b).

\subsection{Description of site and measurements}

Here we introduce the measurements, limitations and assumptions related to our study. The measurements are summarized in Table 1. The measurements were carried out at the boreal forest measurement station SMEAR II (Hyytiälä, $61^{\circ} 51 \mathrm{~N}, 24^{\circ} 17 \mathrm{E}, 181 \mathrm{~m}$ a.s.1.) in Southern Finland. The measurement station is mainly surrounded by a stand of Scots pines with a canopy height around $15 \mathrm{~m}$. A detailed description of the measurement station and equipments is given by Vesala et al. (1998), Kulmala et al. (2001b) and Hari and Kulmala (2005).

The sodar measurements were the most essential measurements in our study. The Sensitron doppler sodar, a $2.3 \mathrm{kHz}$ acoustic sounder, measured the three component wind velocity in the lowest $500 \mathrm{~m}$ of atmosphere at $25-\mathrm{m}$ intervals. The wind data was averaged over a 30 -min period and the means and standard deviations of wind components were saved for every period as well as the echo strength (3-min means). We estimated values of variables at the top of the ABL and for this we needed to know the mixing height. The strength of backscatter depends on the temperature profile. Therefore, an inversion at top of the ABL can be observed and the mix- ing height determined in sodar echo data, as can be seen in Fig. 1b. We determined the mixing height as the height of the maximum echo, as this seems to be the most reliable method (see e.g. Beyrich, 1997; Asimakopoulos et al., 2004). Figure $1 \mathrm{~b}$ highlights how a nocturnal inversion lifts from the ground and breaks during morning hours after the sunrise as the convective boundary layer grows.

The meteorological mast and tower measurements (temperature, humidity, fluxes) were mostly carried out within the surface layer which constitutes the lowest $10 \%$ of the ABL. Temperature and humidity were measured at six levels (4.2, 8.4, 16.8, 33.6, 50.4 and 67.2 m) using ventilated shielded Pt100 sensors and gas analyzers (infrared absorption), respectively. Wind measurements were carried out using an ultrasonic anemometer. We focused on morning hours when the mixing layer growth was intense and the top of the surface layer was probably still below the highest measurement level for temperature and humidity. In addition, we assumed a well-mixed boundary layer in terms of temperature and specific humidity. We used measured values and assumed that the potential temperature and specific humidity are equal to the 67.7-m values in the whole ABL above the surface layer up to the entrainment zone and a capping inversion.

For the boundary layer model (introduced in Sect. 3.2) we needed to know the kinematic heat flux at the surface, $\overline{w^{\prime} \theta^{\prime}}{ }_{s}$ $\left(\mathrm{m} \mathrm{s}^{-1} \mathrm{~K}\right)$. Here $w$ is the vertical velocity and $\theta_{s}$ the potential temperature at the surface. The primes refer to fluctuations from temporal means. The turbulent flux is by definition constant with height in the surface layer and we used the value measured at the height of $23.3 \mathrm{~m}$. In addition, the temperature profile above the ABL was estimated from Tikkakoski radio soundings. The Tikkakoski station $\left(62^{\circ} 24 \mathrm{~N}, 25^{\circ} 41 \mathrm{E}\right)$ is located some $100 \mathrm{~km}$ to the North-East of the SMEAR II station. 
The particle distributions were measured by two differential mobility particle sizers (DMPS) at $2 \mathrm{~m}$ height (see Aalto et al., 2001). The DMPSs had a detection range of 3-10 nm and $10-500 \mathrm{~nm}$ in particle diameter and the time resolution (or the time for one complete size scan) was $10 \mathrm{~min}$. The DMPS data were utilized to estimate the condensation sink profile (see Sect. 3.3) but also to classify the data as event and nonevent days according to the criteria described by Dal Maso et al. (2005).

The sodar is located some $400 \mathrm{~m}$ to the South-West of the location of the mast, tower and particle measurements. Due to the site topography, it is also about $8 \mathrm{~m}$ lower than the mast and tower. However, we assumed that the conditions were similar in the vicinity of the sodar and the mast/tower. We ignored the spatial and altitude difference because the difference is negligible especially due to the used time resolution.

\subsection{Mixed layer model}

Because the mast data and sodar wind fields reached only to 67 and $500 \mathrm{~m}$, respectively, we had to rely on model calculations to get information for the top of the mixed layer and in between. We assumed that the boundary layer was well mixed and used a simple zero-order slab or or jump model. The model has been introduced by several authors (e.g. Stull, 1988). The principle of the model is described shortly here and it is illustrated in Fig. 2.

The height of the boundary or mixed layer $z_{i}$ and potential temperature $\bar{\theta}$ depend merely on the heat flux at the surface $\overline{w^{\prime} \theta^{\prime}}$ and at the top of the atmospheric boundary layer $\overline{w^{\prime} \theta^{\prime}} z_{i}$ :

$z_{i} \frac{d \bar{\theta}}{d t}={\overline{w^{\prime} \theta^{\prime}}}_{s}-{\overline{w^{\prime} \theta^{\prime}}}_{z_{i}}$.

The heat flux at the top of the ABL depends on the entrainment velocity $w_{e}\left(\mathrm{~m} \mathrm{~s}^{-1}\right)$ and the temperature jump or the strength of inversion at the top of the boundary layer $\Delta_{z_{i}} \bar{\theta}$ $(\mathrm{K})$ :

${\overline{w^{\prime} \theta^{\prime}}}_{z_{i}}=-w_{e} \Delta_{z_{i}} \bar{\theta}$.

The entrainment velocity equates to the mixed layer growth velocity, $w_{e}=d z_{i} / d t$. In addition, the strength of the inversion depends on the entrainment velocity, the temperature lapse rate above the mixed layer $\gamma\left(\mathrm{Km}^{-1}\right)$ and the behavior of potential temperature:

$\frac{d \Delta_{z_{i}} \bar{\theta}}{d t}=\gamma w_{e}-\frac{d \bar{\theta}}{d t}$

The equation system is solvable because $\overline{w^{\prime} \theta^{\prime}}$ and $d \theta / d t$ can be estimated from the mast and tower measurements, $d z_{i} / d t$ from the sodar measurements and $\gamma$ from Tikkakoski soundings. A similar equation system can be written for specific humidity $q\left(\mathrm{~kg} \mathrm{~kg}^{-1}\right)$ if $\theta$ is substituted by $q$. Solving the system leads to temperature (specific humidity) profiles at all the time steps. In addition, we get estimations for variables at the top of the mixed layer, ${\overline{w^{\prime} \theta^{\prime}}}_{z_{i}}$ and $\Delta_{z i} \bar{\theta}$, which are crucial to our study.

\subsection{Condensation sink profile}

The vapor concentration is reduced due to condensation on preexisting particles. The condensation sink CS (see Kulmala et al., 2001a) depends on particle surface area i.e. particle size distribution. The dry particle size spectrum was measured by the DMPS system and it was converted to a wet particle size distribution following Laakso et al. (2004) and using the calculated humidity profiles. The conversion is based on measured dry and wet particle size distributions at SMEAR II station and it is a function of particle distribution at dry conditions and RH. Besides particle size distribution, the condensation rate depends on the velocity of molecules and thereby temperature. CS can be calculated when the particle number size distribution $d N / d \log D_{p}$, temperature $T$ and relative humidity RH are known. These all were measured at SMEAR II station in the surface layer and a CS profile was estimated as described below.

The condensation sink profiles were estimated using measured values and some assumptions. As mentioned above, we assumed that diabatic heating can be ignored and thereby potential temperature $\theta$ and specific humidity $q$ are constant in an ascending air parcel. In addition, we assumed that the number distribution of particles did not change substantially due to aerosol dynamics. However, the hygroscopic growth of particles with changing $\mathrm{RH}$ was taken into account when the measured dry diameters were corrected to wet diameters. In addition, an ascending air parcel expands adiabatically due to pressure drop and this effect was also included. In an adiabatic process the total energy does not change. Using the given assumptions, relationships and the equation of state, the particle number distribution at a level $z$ was given by $\left(d N / d \log D_{p}\right)_{z}=\left(d N / d \log D_{p}\right)_{s}\left(T_{z} / T_{s}\right)^{c_{v} / R_{\text {air }}}$. $\left(d N / d \log D_{p}\right)_{s}$ is the measured particle distribution at the surface, $c_{v}$ is the specific heat capacity in a constant volume and $R_{\text {air }}$ is the universal gas constant divided by the mole mass of air $\left(R / M_{\text {air }}\right)$. The equation describes the decrease of particle number concentration in an ascending air parcel.

The expansion of an air parcel leads to a temperature drop and an increase of the saturation ratio $S$ through decrease of $e_{\text {sat }}(T)$. The temperature drop itself decreases CS, while the increasing relative humidity leads to an increase of CS. On the other hand, the decrease of particle concentration due to the adiabatic expansion decreases the sink. We show the significance of these factors $\left(T, \mathrm{RH}\right.$ and $\left.d N / d \log D_{p}\right)$ for the CS in Sect. 4.2.

\subsection{Statistical tools}

We compared sodar data of event and nonevent days and carried out a two-sample paired signed rank test, which is the 
(a)

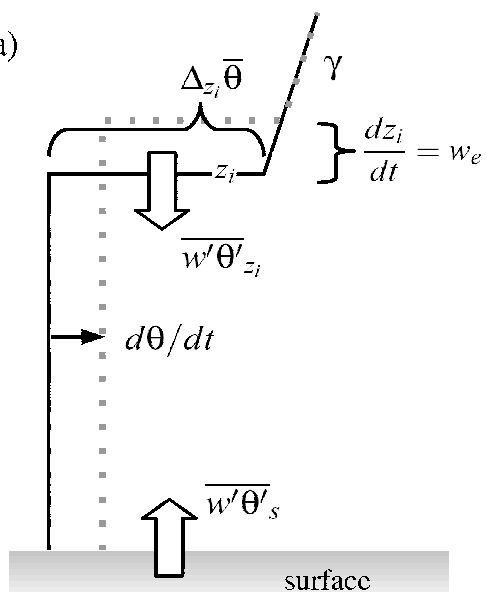

(b)

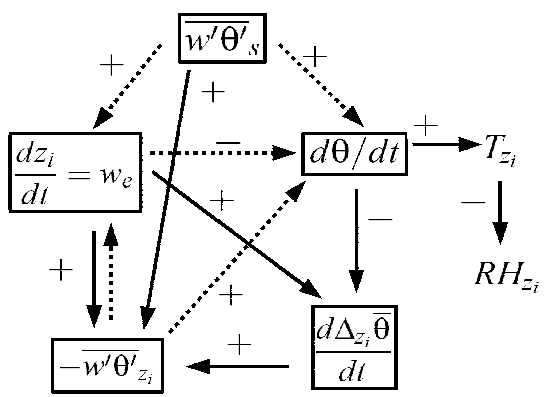

Fig. 2. (a) The zero-order jump model assumes that the inversion at the top of the ABL is sharp (no entrainment zone). The solid and dotted curves indicate potential temperature profiles. (b) The flow chart shows how the variables affect each other. The model includes processes or effects drawn with a solid line while the dashed line effects have been excluded. See Sect. 3.2 for an explanation of the notation.

nonparametric analog to the paired two-sample $t$-test. Similarly to $t$-test, two data sets can be compared and it can be investigated whether the medians (means) differ significantly. We knew half an hour mean values $\bar{x}(t, z)$ for every time period $t$ and measurement level $z$ on a single day. Then we calculated a separate mean $(<>)$ over event and nonevent days for every $(t, z)$-grid point. Now the event and nonevent day values constituted $(t, z)$-pairs. A paired test has a similar procedure as an unpaired and one-sample test but instead of testing medians or means, the mean difference between values is calculated and tested whether it differs from zero (cf. a one-sample test). The paired signed rank test is not as effective as the $t$-test but our data sets do not fulfill all assumptions (e.g. data distributed normally) required in the $t$-test. However, the distributions that we investigated appeared to be symmetrical.

The studied response is binomial because a nucleation event occurs or it does not. The probability of an event $p(y=1 \mid \boldsymbol{x})$ can be presented by a continuous function which takes values between 0 and 1 :

$p(y=1 \mid \boldsymbol{x})=\frac{1}{1+\exp \left\{-\left(\beta_{0}+\boldsymbol{x}^{\prime} \boldsymbol{\beta}\right)\right\}}$

Here $\boldsymbol{x}$ is the vector of variables, $\beta_{0}$ is the intercept and $\boldsymbol{\beta}$ the vector of slope parameters. The method is called binomial logistic regression and it has been utilized to study which variables could describe the new particle formation probability. The accuracy of a regression model raises if the number of variables is increased. On the other hand, this leads to a more complicated but not necessarily significantly better model.

\section{Results}

We compared the mean conditions between event and nonevent days. First, the strength of turbulent mixing was compared and then we continued testing the difference in $P_{\text {met }}-C S=\left(-\frac{\Delta H_{o s}}{R T^{2}} \frac{d T}{d t}-C S\right)$, which refers to the terms at the right hand side parenthesis in Eq. (1), the effect of meteorology $P_{\text {met }}$ and condensation sink CS. We concentrated on morning hours between 6 and 12 local winter time (LT) which is the probable onset time for a nucleation event. In addition, we have presented a case study on 29 March 2003. Finally we have discussed which variables could be the best indicators of new particle formation.

\subsection{Observed intensity of mixing in the ABL}

The turbulent kinetic energy $\left(k=\frac{1}{2}\left(\overline{u^{\prime 2}}+\overline{v^{\prime 2}}+\overline{w^{\prime 2}}\right)\right)$ indicates the strength of mixing. The standard deviations of the wind components $(u, v, w)$ were given by the sodar measurements and we compared the magnitude of the vertical component, $\sigma_{w}=\sqrt{\overline{w^{\prime 2}}}$, between event and nonevent days. The mean standard deviation of vertical velocity was calculated over event and nonevent days during morning hours 06:00 12:00 LT. Every $<\overline{\sigma_{w}}>(t, z)$ value corresponded to a mean over 30 min $\left(^{-}\right)$at a specific time point $t$ and altitude $z$. Subsequently we calculated means over event and nonevent days $(<>)$.

The sodar was not able to observe above the capping inversion. Therefore data from the highest measurement altitudes was sometimes missing. Only $(t, z)$-data points which covered at least data for 10 days were included in this study. This led to the exclusion of data especially from the altitudes above $350 \mathrm{~m}$ in the early morning hours. The sodar's range grows to higher altitudes as the ABL grows. At the same time, mixing strengthens. These properties of the ABL 

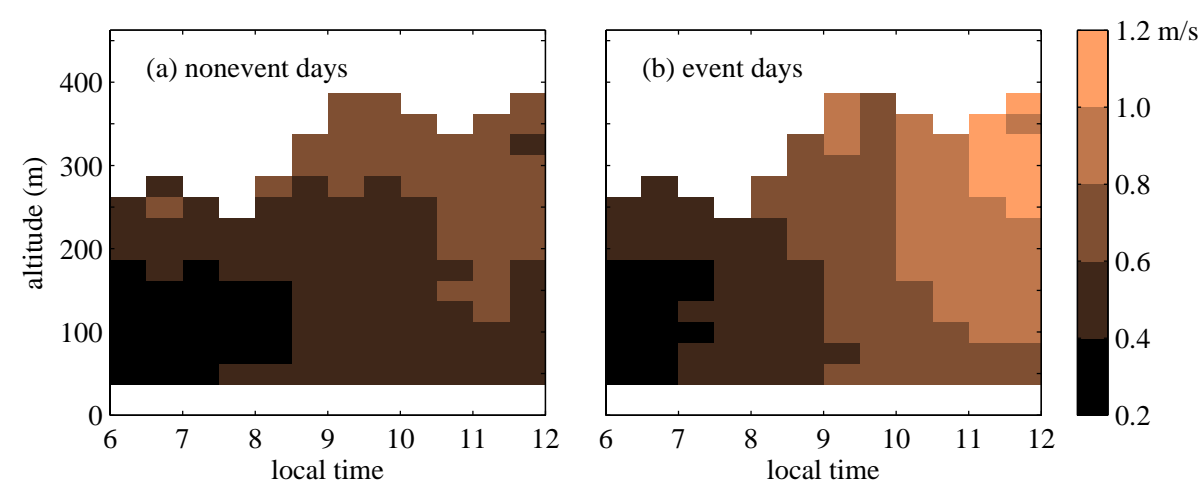

Fig. 3. The average standard deviation of vertical velocity $<\overline{\sigma_{w}}>(t, z)$ on (a) the nonevent days and (b) event days observed by the sodar in Hyytiälä.
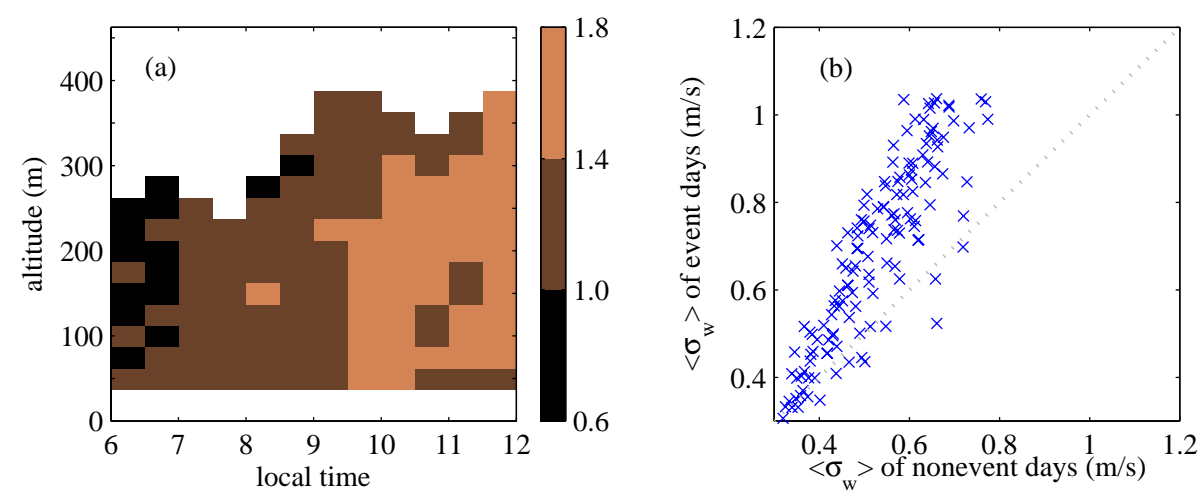

Fig. 4. (a) The ratio of event day values and nonevent day values of $<\overline{\sigma_{w}}>(t, z)$ and (b) the event day values (Fig. 3b) vs. the nonevent day values (Fig. 3a). The dotted line is 1:1-relationship.

(growth and strengthening) can be seen in Fig. 3, where the average behavior of $\overline{\sigma_{w}}(t, z)$ on the nonevent and event days is presented. Figure $4 \mathrm{a}$ shows the ratio of event and nonevent day values of $<\overline{\sigma_{w}}>(t, z)$. The values of $<\overline{\sigma_{w}}>(t, z)$ are on average $36 \%$ higher on the event than on the nonevent days but the ratio increases as the ABL grows. This indicates that the mixing is not only stronger but also strengthens faster on the studied event days. Strong mixing on event days may be connected to cold fronts. It could be interesting to study if synoptic conditions explain the mean difference in mixing strength.

Figure $4 \mathrm{~b}$ shows the event day values versus the nonevent day values of $<\overline{\sigma_{w}}>(t, z)$. The values constitute $(t, z)$-pairs which can be used to test the significance of the difference between mean conditions using the paired test(s) introduced in Sect. 3.4. According to the paired tests the difference is significant $(p<0.001, n=138)$ and thereby, the mixing has been stronger on the studied event than on the nonevent days.

Our results agree with the results presented by Nilsson et al. (2001b). The authors studied data measured during BIOFOR (Biogenic aerosol formation in the boreal forest) campaign and concluded that the turbulent kinetic energy was approximately double on event days in comparison to nonevent days. They concentrated on situations with a cold outbreak. The synoptic conditions could often be similar in our cases, as our data was confined to meteorological situations typical for a clear sky continental boundary layer, with a transition from stable to unstable conditions in the morning, followed by increasing turbulence and convection. The onset and strength of turbulence are connected to shortwave radiation which could partly explain the difference between event and nonevent day mixing conditions. Therefore it would be interesting to compare the time of sunrise and onset of turbulence with the onset of particle formation.

\subsection{Theoretical change of saturation}

A simple theoretical study has been conducted in order to assess the magnitude of condensation sink and vertical flow in the ABL and how important the factors CS and $P_{\text {met }}$ are at different levels of the ABL. CS is always positive and resists saturation whereas the latter term may be positive or negative depending on the direction of vertical mean flow which affects $S_{o s}$ through the temperature term $d T / d t$.

We studied separately the effect of temperature, humidity and expansion of an air parcel on CS on 29 March 2003 

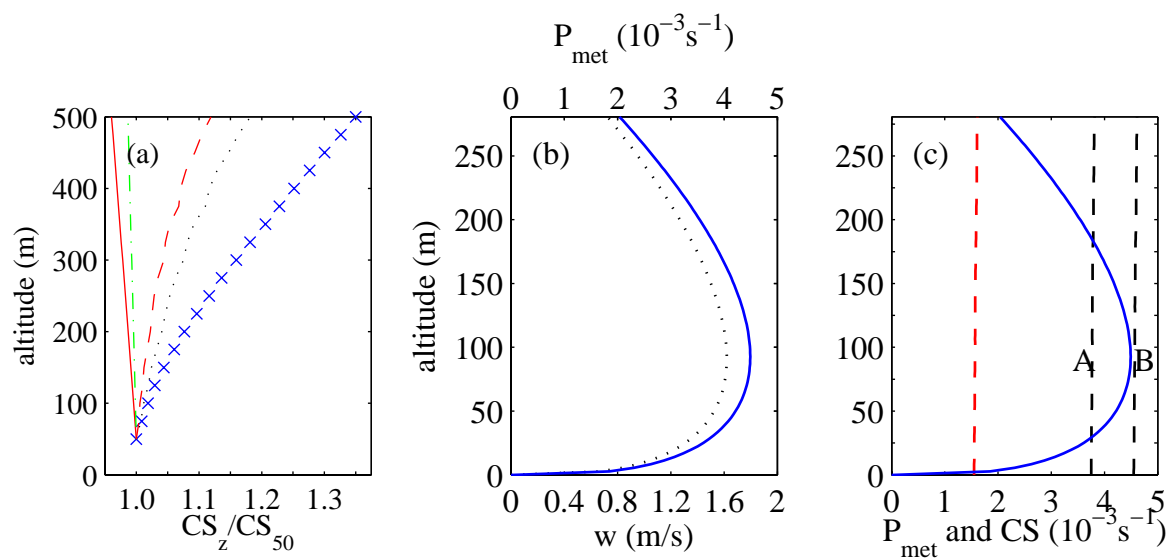

Fig. 5. (a) The influence of increase of RH (dotted curve), decrease of $T$ (green dash-dotted curve) and decrease of $\left(d N / d \log D_{p}\right)_{z}($ red solid curve) on CS in an ascending air parcel. The total effect is represented by a red dashed curve and the profiles are based on surface measurements on 29 March 2003. The crosses are mean values for all the studied data and all the values have been scaled by $\mathrm{CS}_{50 \mathrm{~m}}$. (b) The theoretical $P_{\text {met }}$ profile (solid curve) based on a parametrized vertical velocity profile (dotted curve) and surface measurements on 29 March $2003\left(\theta=276 \mathrm{~K}, z_{i}=327 \mathrm{~m}, \overline{w^{\prime} \theta^{\prime}}{ }_{s}=0.04 \mathrm{~m} \mathrm{~s}^{-1} \mathrm{~K}\right)$. (c) $P_{\text {met }}$ (blue solid curve) and CS (red dashed curve, the total effect in Fig. 5a), which is based on measurements and two theoretical profiles of CS (dashed curves A and B).

and the results are presented in Fig. 5a. When the relative humidity increased from 36 to $47 \%$ the condensation sink increased by only $15 \%$ which was a relatively negligible effect. The cooling and air parcel expansion were proved to be of lesser importance since they only slightly decreased CS. The dotted curve in Fig. 5a shows the overall effect when all the three factors have been taken into account and the dots are the mean values calculated over all the studied days. According to our simulations, CS mainly increases while the air parcel rises. The condensation sink may increase some tens of percents in the first $500 \mathrm{~m}$ and therefore a surface value of CS is not an adequate estimate of the condensation sink at elevated altitudes in all cases, but probably an approximation good enough for most studies. We have considered an ascending air parcel but the result can be generalized to relate the CS profile in a well-mixed ABL.

The effect of meteorology $\left(P_{\mathrm{met}}=-\frac{\Delta H_{o s}}{R T^{2}} \frac{d T}{d t}=-\frac{\Delta H_{o s}}{R T^{2}} \Gamma w\right)$ depends on the vertical velocity $w$ and the temperature lapse rate $\Gamma$, which is constant if no change of state occurs for water. In order to estimate the mean vertical velocity we used a similarity relationship for vertical velocity in a mixed layer presented by Young (1988):

$\bar{w}=0.82 w_{*}\left(z / z_{i}\right)^{1 / 3}\left(1.3-z / z_{i}\right)$

In addition to the height of the ABL, the wind profile depends on the convective velocity scale $w_{*}=\left(g / \theta z_{i} \overline{w^{\prime} \theta^{\prime}}{ }_{s}\right)^{1 / 3}$, which implies that $\bar{w}$ depends strongly on $\overline{w^{\prime} \theta^{\prime}}$, the energy source for convection. The equation results in a peak value of $\bar{w}$ at the height of $z_{i} / 3$.

The parametrized $P_{\text {met }}$ profile follows the shape of the vertical wind velocity due to the constant temperature lapse rate. Figure $5 \mathrm{~b}$ shows that the maximum effect is located just above the vertical wind maximum and achieves a value of $4 \times 10^{-3} \mathrm{~s}^{-1}$ on the simulated case study day. As Anttila et al. (2004) concluded, this value is of the same magnitude as the observed condensation sinks. The maximum effect or $(d S / d t)_{\max }$ is given by the equation

$z_{i}=\frac{2 z_{\max }\left(-2 T_{s}+\Gamma z_{\max }\right)}{1.3\left(-T_{s}+5 \Gamma z_{\max }\right)}$

where $z_{\max }$ is the altitude of the maximum effect. In the studied conditions (chosen to be $240 \leq \bar{\theta} \leq 300 \mathrm{~K}$ and $400 \leq z_{i} \leq 2400 \mathrm{~m}$ as these cover most of the local situations) the maximum is located between $0.33 z_{i}$ and $0.38 z_{i}$, in other words about $1 / 3$ of the mixing height. The vertical position of the maximum value rises if $z_{i}$ increases or $\theta$ decreases. It is important to note that the saturation ratio in an ascending air parcel continues to increase above $z_{\max }$ and onset of particle formation may happen at any altitude below or above $z_{\text {max }}$ if $P_{\text {met }}$ is large enough to overcome CS.

The entire term $P_{\text {met }}-C S$ has been considered next with three basically different cases exhibited in Fig. 5c. The first case is based on observations and the two theoretical ones are presented to consider other possible situations. In the case based on observations $P_{\text {met }}$ exceeds CS and saturation ratio increases continuously when an air parcel rises in the ABL. In this case new particle formation is possible in the whole ABL. The theoretical case A represents a situation when $P_{\text {met }}$ exceeds CS only at limited altitudes and therefore the saturation ratio increases only nearby the maximum of $P_{\text {met }}$. In both of the cases introduced above, new particle formation is possible at the elevated heights even if it does not occur at the surface. If instead CS exceeds $P_{\text {met }}$ at all altitudes, it leads to a decrease of saturation ratio in the entire parcel like case B. In this case, new particle formation is not possible if it does not occur at the surface, in the vicinity of sources. 

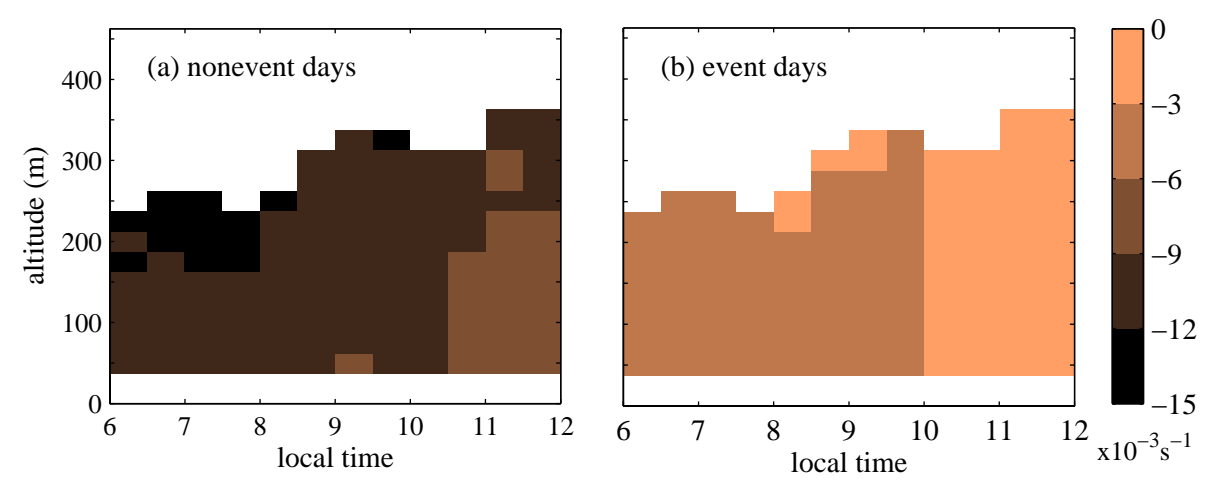

Fig. 6. The mean effect of temperature change (or vertical draft) and condensation sink $<P_{\text {met }}-C S>(z, t)$ on $d S_{o e} / d t$ on the studied (a) nonevent days and (b) event days.

In the presence of sources, which we have previously neglected, we are probably closer to case A and the observation based scenario which enable new particle formation at elevated altitudes. The source term $Q$ in Eq. (1) would modify the following Eqs. (2) and (3) in such away that case B would turn into case A or even cause aerosol formation at all levels. Given that event days are also often days with large organic emission (e.g. Janson et al., 2001) this is probably frequently the case.

\subsection{Saturation ratio of an organic vapor based on observa-} tions

The saturation ratio of an organic vapor increases when the positive effect of vertical motion (and hence decreasing of temperature) exceeds the influence of preexisting aerosols through condensation sink. As also suggested by Anttila et al. (2004), the theoretical study based on surface observations showed that the vertical ascending motion can lead to an increase of the saturation ratio. The theoretical results encourage us to study whether $S_{o s}$ increases due to the observed eddies and whether there is a difference in $d S_{\text {os }} / d t$ between event and nonevent days observed in Hyytiälä.

Equation (8) represents the empirical mean conditions of vertical velocity. However, $w$ may be locally and momentarily much higher and updraft may be strong enough to lead to new particle formation. The vertical velocity was given by sodar measurements. The wind velocity varies during 30-min measurement period. Instead of the mean vertical velocity $\bar{w}$ we used a higher value $\bar{w}+\sigma_{w}$, where $\sigma_{w}$ is the standard deviation of wind velocity. If the velocity follows a normal distribution, the distribution predicts that $w$ is $\bar{w}+\sigma_{w}$ or higher during $5 \mathrm{~min}$ of measurement period. The distribution of vertical wind velocity in the convective boundary layer is positively skewed especially near the boundary layer top (see e.g. Cheinet, 2003) which means that strong updrafts are even more common than a normal distribution would predict. Therefore, the adopted higher value is justified in order to investigate the possible effect of strong local updrafts.
Figure 6 shows the mean values of $\left\langle P_{\text {met }}-C S>(t, z)\right.$ on the nonevent (a) and event (b) days between 06:00 and 12:00 LT. Even on the event days the effect of temperature lapse does not overcome the effect of condensation sink on saturation ratio. The mean total effect is negative and the saturation ratio decreases, instead of increasing. Even if $P_{\text {met }}$ does not exceed the effect of CS on the event days, convection has made saturation conditions more favorable than for the nonevent days so that a smaller source would enable growth and activation. We can estimate the relative source strength $Q /\left(C_{0} S_{o s}\right)$ (the first right hand side term of Eq. (1), but normalized by the saturation ratio) that would be needed on average to get a positive change of saturation ratio and hence possible aerosol formation to about $1-2 \times 10^{-3} \mathrm{~s}^{-1}$ on event days. The required relative source on nonevent days is correspondingly over $6 \times 10^{-3} \mathrm{~s}^{-1}$. The mean surface value of CS on the nonevent and event days was $8.9 \times 10^{-3} \mathrm{~s}^{-1}$ and $4.7 \times 10^{-3} \mathrm{~s}^{-1}$, respectively. If we compare these numbers to Fig. 6, we see that the vertical motion (term $P_{\text {met }}$ ) does not only enhance saturation on the event days, it also seems to prevent new particle formation on the nonevent days.

Figure 7 clearly illustrates the difference between the nonevent and event days. As above with $\left\langle\sigma_{w}\right\rangle$ values, the difference between the mean values increases when the ABL grows. Similarly to $\left\langle\sigma_{w}\right\rangle$ data we have carried out statistical test(s) using $<P_{\text {met }}-C S>(t, z)$ pairs and according to the test(s) there is statistical significance in the difference between the event and nonevent day conditions $(p<0.001$, $n=126)$.

Even though the saturation ratio seems to generally decrease and thereby inhibit new particle formation, a local $S_{o s}$ may increase significantly on individual days due to large eddies. Figure 8 shows an example when $P_{\text {met }}$ exceeds CS and $S_{o s}$ increases by as high as a factor of 1.25 . If we assume that vertical velocity and temperature lapse rate are constant in an observed 25-m layer, we can apply Eq. (3) in our calculations. During the day convection and mixing were strong. The half an hour mean of vertical velocity $\bar{w}$ was between 

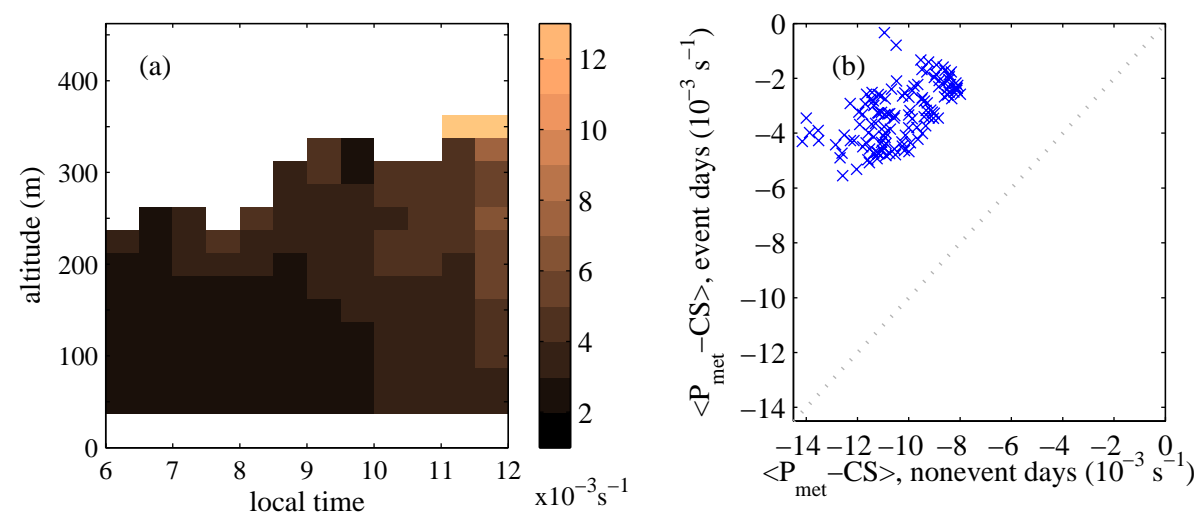

Fig. 7. (a) The difference between $<P_{\text {met }}-C S>(t, z)$ values on the event and nonevent days (event day values minus nonevent day values) and (b) the value of $\left\langle P_{\mathrm{met}}-C S>(t, z)\right.$ on the event days (Fig. 6b) vs. the nonevent day values (Fig. 6a).

Table 2. Correlations between the selected variables.

\begin{tabular}{lllllll}
\hline$d \theta / d t$ & 0.21 & & & & & \\
$\exp \left(C S_{z_{i}}\right)$ & -0.17 & -0.13 & & & & \\
$\exp \left(P_{\text {met }, z_{i}}\right)$ & 0.20 & 0.18 & -0.23 & & & \\
$T_{z_{i}}$ & 0.077 & 0.16 & 0.0050 & -0.13 & & \\
$\mathrm{RH}_{z_{i}}$ & 0.053 & -0.49 & 0.084 & 0.095 & -0.20 & \\
$-\bar{w}^{\prime} \theta^{\prime}$ & 0.45 & 0.73 & -0.21 & 0.36 & 0.094 & -0.14 \\
& $w_{e}$ & $d \theta / d t$ & $\exp \left(C S_{z_{i}}\right)$ & $\exp \left(P_{\text {met }, z_{i}}\right)$ & $T_{z_{i}}$ & $\mathrm{RH}_{z_{i}}$ \\
\hline
\end{tabular}

-1.1 and $0.3 \mathrm{~m} \mathrm{~s}^{-1}$ but $\sigma_{w}$ was as high as $1.37 \mathrm{~m} \mathrm{~s}^{-1}$ (it is hereby reminded that $\bar{w}+\sigma_{w}$ was used in Eq. (3) instead of $\bar{w})$. We have included only the lowest $400-500 \mathrm{~m}$ of the boundary layer in the current study but the mixing happens in a larger layer due to the growth of the ABL. Hence the effect has probable been underestimated.

\subsection{Probability of particle formation}

We have continued with a statistical study to increase insights into which meteorological variables may be crucial for new particle formation. This enables us to make valuable inferences on earlier studies, despite the limited amount of our data set: only 80 cases including 65 event and 15 nonevent days. The size of data set decreased from 100 to 80 cases due to missing mast and tower data on 20 days. Buzorius et al. (2003) and Hyvönen et al. (2005) attempted to express the probability of a nucleation event as a function of measured variables. However, the earlier studies utilized solely surface measurements at SMEAR II station while in the current study we have concentrated on variables at the top of the ABL.

Several variables were calculated at the same time, approximately three hours after sunrise. We considered correlations between variables to choose the most adequate variables, presented in Table 2. Then two variables at a time were chosen for a logistic regression analysis and all possible combinations of variables were tested. We compared associ-

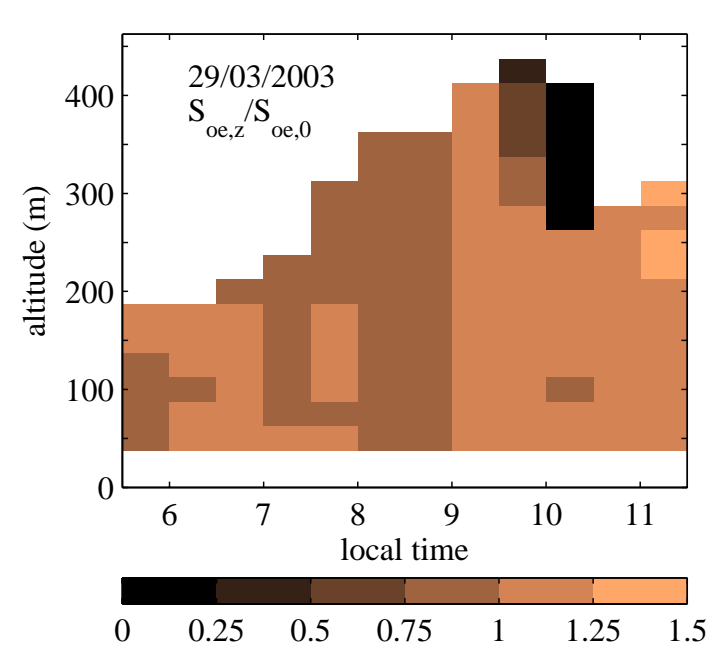

Fig. 8. The cumulative effect of condensation sink and vertical motion (temperature change) on saturation ratio $S_{o e, z} / S_{o e, 0}$ on 29 March 2003. $S_{o e, 0}$ is the saturation ratio just below the sodar measurements.

ations of predicted probabilities and observed responses or how many times a predicted probability (given by Eq. 7) of observed new particle formation was higher than the probability for a nonevent day (with 65 event and 15 nonevent cases we got $65 \times 15=975$ couples). Based on these levels of 


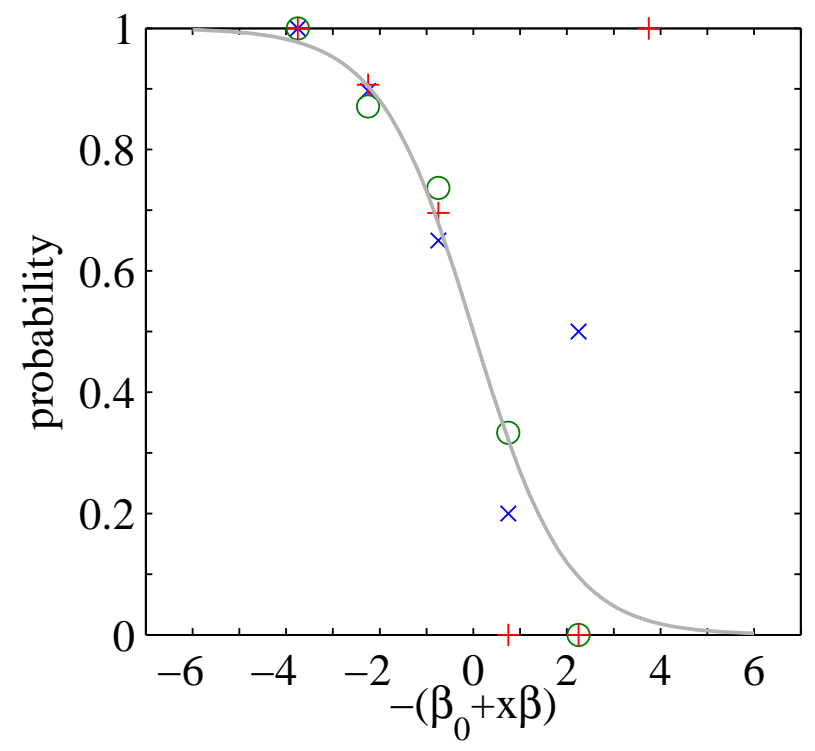

Fig. 9. The probability of new particle formation ( $\left.p_{\text {event }}\right)$ as a function of selected variables. The curve is the logistic model and the markers show the proportion of observed event cases of all the cases when three different couples of variables have been used as indicators or variables in the model: $\times$ corresponds to the couple $\exp \left(C S_{z_{i}}\right)$ and $d \theta / d t$, 。 represents $\exp \left(C S_{z_{i}}\right)$ and $\mathrm{RH}_{z_{i}}$ and $+\operatorname{shows} \exp \left(C S_{z_{i}}\right)$ and $-\overline{w^{\prime} \theta^{\prime}} z_{i}$.

concordance we chose the best variables which depicted the nucleation probability.

The most effective couple appeared to be $\exp \left(C S_{z_{i}}\right)$ and $d \theta / d t$. The probability of nucleation is given by

$$
p_{\text {event }}=\frac{1}{1+\exp \left(-2.0506+0.8229 \exp \left(C S_{z_{i}}\right)-1.2628 \frac{d \theta}{d t}\right)} \text {. }
$$

which in $89 \%$ of cases gave a higher probability to an event than to a nonevent day. Almost as successful results were produced by $\exp \left(C S_{z_{i}}\right)$ with $-\overline{w^{\prime} \theta^{\prime}} z_{i}$ or $\mathrm{RH}_{z_{i}}$. These couples had 85 and 86 percent concordance rate, respectively. Figure 9 shows the logistic regression model and how the probabilities calculated from the actual data follow the model. The factors for Eq. (7) and the concordance values have been collected into Table 3 . The variables $d \theta / d t,-\overline{w^{\prime} \theta^{\prime}} z_{i}$ and $\mathrm{RH}_{z_{i}}$ were correlated (see Table 2) and therefore e.g. dependency on $d \theta / d t$ may reflect an effect which originates from RH. Also triplets of variables were constructed, but the level of concordance did not increase considerably but remained below $91 \%$.

Buzorius et al. (2003) utilized over three times larger data set of Hyytiälä measurements in comparison to our data set and and succeeded in representing the new particle formation probability as a function of heat flux at the ground and some other heat flux related parameters, namely water vapor concentration, the variance of vertical wind speed and temperature standard deviation in the surface layer. They also highlighted the connection between the observed condensation sink and the probability. Given that the heat flux at the mixed layer top is driven by the heat flux at the ground and given that the calculated $\exp \left(C S_{z_{i}}\right)$ is largely based on the condensation sink at the ground, it is possible that the identification of $-\overline{w^{\prime} \theta^{\prime}} z_{i}$ as a key factor together with $\exp \left(C S_{z_{i}}\right)$ is agreement with the conclusions by Buzorius et al. (2003). Hyvönen et al. (2005) concluded that the most crucial variables in their study were condensation sink and humidity, which both oppose new particle formation. Our results endorse these observations and studies, even if we have concentrated on variables aloft within the ABL.

In Finnish conditions, mixing decreases preexisting particle concentration (CS) and $\mathrm{RH}$ as cleaner and drier air above the $\mathrm{ABL}$ is mixed to the boundary layer and thereby new particle formation would be more probable. The event observations depend on real factors in the $\mathrm{ABL}$, e.g. entrainment and dilution. Even if our model does not include the effect of dilution, we know that this is correlated with the simulated entrainment velocity and we can draw conclusions based on this. Our study indicates that entrainment inhibits particle formation $\left(\beta<0\right.$ for $w_{e}$ in Eq. 7), despite the fact that it could be expected that the probability increases due to decreasing preexisting particle concentration if entrainment velocity increases. This can be understood as the ABL grows fast also temperature is lower and $\mathrm{RH}$ is higher at the top of the ABL (the top of the ABL is located higher and therefore it is probably colder). In addition, the sources of organic vapors are located at the surface and therefore entrainment also leads to dilution of organic vapors. This could be one explanation for our projected inference that strong growth of the ABL inhibits new particle formation.

Another interesting result is that the probability increases if temperature is higher at the top of the $\mathrm{ABL}, p_{\text {event }}$ is positively correlated with high $d \theta / d t, T_{z_{i}}$ and a strong heat flux downwards. Also this dependency could be explained by $\mathrm{RH}$ as higher temperature leads to lower RH. A strong heat flux at the top of the boundary layer (high absolute value of \left.$-{\overline{w^{\prime} \theta^{\prime}}}_{z_{i}}\right)$ but slow increase of the $\operatorname{ABL}(d z / d t$ small) indicates, that a strong inversion at the top of the ABL would boost new particle formation.

It is noteworthy that de Leeuw et al. (2002) concluded that they did not find a clear connection between particle formation and vertical wind velocity in a coastal zone but the dynamic conditions (shallow internal boundary layer driven by the change in surface properties from ocean to land) differ substantially from Hyytiälä. In addition, Mikkonen et al. (2006) concluded that ozone was an important indicator in Po Valley, Italy. Ozone may be a tracer of entrainment but in polluted regions as Po Valley, it is more likely a tracer of anthropogenic activities. 
Table 3. The values of factors $\beta_{0}$ and $\boldsymbol{\beta}$ in Eq. (7) and the percent concordance values, when a logistic regression analysis has been carried out using two normalized variables at a time. Every column of numbers corresponds to one logistic regression model. The mean values and standard deviations before a normalization have been given in brackets after the variables.

\begin{tabular}{llrrr}
\hline variable & & \multicolumn{3}{r}{$\beta_{0}$ and $\boldsymbol{\beta}$} \\
\hline$\beta_{0}$ & & 2.0506 & 1.7394 & 2.1205 \\
$\exp \left(C S_{z_{i}}\right)$ & $\left(1.007,7.3 \times 10^{-3}\right)$ & -0.8229 & -0.8246 & -0.8734 \\
$d \theta / d t$ & $\left(4.19 \times 10^{-4} \mathrm{~K} \mathrm{~s}^{-1}, 2.3 \times 10^{-4} \mathrm{~K} \mathrm{~s}^{-1}\right)$ & 1.2628 & & \\
$-\overline{w^{\prime} \theta^{\prime}} z_{i}$ & $\left(0.0424 \mathrm{~K} \mathrm{~m} \mathrm{~s}^{-1}, 0.0421 \mathrm{~K} \mathrm{~m} \mathrm{~s}^{-1}\right)$ & & 0.6716 & \\
$\mathrm{RH}_{z_{i}}$ & $(76.1 \%, 16.1 \%)$ & & & -1.3270 \\
\hline concordance & & $89 \%$ & $85 \%$ & $86 \%$ \\
\hline
\end{tabular}

\section{Conclusions}

We have compared conditions in the lowest $500 \mathrm{~m}$ of the ABL between new particle formation days and nonevent days. According to our results, the mixing is stronger on observed event than on nonevent days which leads to higher saturation ratio of organic vapors due to the vertical motion. The effect of sources and entrainment of drier and cleaner air at the top of the boundary layer were ignored in our study. If these were included, the positive effect of sources and temperature lapse on vapor concentration would probably exceed the influence of the condensation sinks on a regular basis. We believe that the results can be generalized to other measurements sites where clean air is mixed at the top of the ABL. In the future it would be interesting to study how the saturation ratio profile behaves when the effect of vertical mixing, sources and condensation sink have been simulated simultaneously.

Furthermore, the effect of the total mixed layer depth was ignored as the sodar measurements extended to $500 \mathrm{~m}$. According to our study, the saturation ratio may increase by $25 \%$ due to vertical eddies. We have studied only the first $500 \mathrm{~m}$ and already this lift leads to saturation if the saturation ratio at the surface is at least 0.8 . Furthermore, our simulations were based on 30-min means of variables and spatial and temporal variation may be even larger than we estimated.

We attempted to define indicators for new particle formation focusing on conditions at the top of the atmospheric boundary layer. Even though the data set was limited, we succeeded in finding a probability dependency of the variables. As in earlier studies, the most important variables were the ones that inhibited new particle formation. This supports the hypothesis that nanoclusters exist but grow only in specific conditions (see e.g. Kulmala et al., 2000; Kulmala et al., 2006). These conditions have been related to solar radiation and small condensation sink, and as we have shown here also on boundary layer dynamics.

It is recommended to extend the studied variables from the most common surface measurements and study several fluxes (in addition to sensible heat also latent heat, gases, particles) at the top of the atmospheric boundary layer in different boundary layer environments. It is also suggested that larger data sets are utilized.

Acknowledgements. We wish to acknowledge the Nordic Center of Excellence BACCI (the Nordic Council of Ministers) and the Swedish Research Council for financial support of this study.

Edited by: J. Quaas

\section{References}

Aalto, P., Hämeri, K., Becker, E., Weber, R., Salm, J., Mäkelä, J., Hoell, C., O’Dowd, C., Karlsson, H., Väkevä, M., Koponen, I. K., Buzorius, G., and Kulmala, M.: Physical characterization of aerosol particles during nucleation events, Tellus, 53B, 344-358, 2001.

Anttila, T., Kerminen, V.-M., Kulmala, M., Laaksonen, A., and O'Dowd, C. D.: Modelling the formation of organic particles in the atmosphere, Atmos. Chem. Phys., 4, 1071-1083, 2004, http://www.atmos-chem-phys.net/4/1071/2004/.

Asimakopoulos, D. N., Helmis, C. G., and Michopoulos, J.: Evaluation of SODAR methods for the determination of the atmospheric boundary layer mixing height, Meteorol. Atmos. Phys., 85, 85-92, 2004.

Beyrich, F.: Mixing height estimation from SODAR data - A critical discussion, Atmos. Environ., 31, 3941-3953, 1997.

Buzorius, G., Rannik, Ü., Aalto, P., Dal Maso, M., Nilsson, E. D., Lehtinen, K. E. J., and Kulmala, M.: On particle formation prediction in continental boreal forest using micrometeorological parameters, J. Geophys. Res., 108, 4377, doi:10.1029/2002JD002850, 2003.

Cheinet, S.: A Multiple Mass-Flux Parameterization for the Surface-Generated Convection, Part I: Dry Plumes, J. Atmos. Sci., 53B, 2313-2327, 2003.

Dal Maso, M., Kulmala, M., Riipinen, I., Wagner, R., Hussein, T., Aalto, P. P., and Lehtinen, K. E. J.: Formation and growth of fresh atmospheric aerosols: eight years of aerosols size distribution data from SMEAR II, Hyytiälä, Finland, Boreal Environ. Res., 10, 323-336, 2005.

de Leeuw, G., Kunz, G. J., Buzorius, G., and O'Dowd, C. D.: Meteorological influences on coastal new particle formation, J. Geophys. Res., 107, 8102, doi:10.1029/2001JD001478, 2002. 
Easter, R. C. and Peters, L. K.: Binary Homogeneous Nucleation: Temperature and Relative Humidity Fluctuations, Nonlinearity, and Aspects of New Particle Production in the Atmosphere, J. Appl. Meteorol., 33, 775-784, 1994.

Hari, P. and Kulmala, M.: Station for Measuring EcosystemAtmosphere Relations (SMEAR II), Boreal Environ. Res., 10, 315-322, 2005.

Hirsikko, A., Laakso, L., Hõrrak, U., Aalto, P. P., Kerminen, V.M., and Kulmala, M.: Annual and size dependent variation of growth rates and ion concentrations in boreal forest, Boreal Environ. Res., 10, 357-369, 2005.

Hyvönen, S., Junninen, H., Laakso, L., Dal Maso, M., Grönholm, T., Bonn, B., Keronen, P., Aalto, P., Hiltunen, V., Pohja, T., Launiainen, S., Hari, P., Mannila, H., and Kulmala, M.: A look at aerosol formation using data mining techniques, Atmos. Chem. Phys., 5, 3345-3356, 2005,

http://www.atmos-chem-phys.net/5/3345/2005/.

Janson, R., Rosman, K., Karlsson, A., and Hansson, H.-C.: Biogenic emissions and gaseous precursors to forest aerosols., Tellus, 53B, 423-440, 2001.

Kerminen, V.-M. and Wexler, A. S.: Enhanced formation and development of sulfate particles due to marine boundary layer circulation, J. Geophys. Res., 100, 23 051-23 062, 1995.

Kerminen, V.-M., Pirjola, L., and Kulmala, M.: How significantly does coagulational scavenging limit atmospheric particle production?, J. Geophys. Res., 106, 24 119-24 126, 2001.

Khosrawi, F. and Konopka, P.: Enhanced Particle Formation and Growth Due to Mixing Processes in the Tropopause Region, Atmos. Environ., 37, 903-910, 2003.

Kulmala, M.: How Particles Nucleate and Grow, Science, 302, 1000-1001, 2003.

Kulmala, M., Pirjola, L., and Mäkelä, J. M.: Stable sulphate clusters as a source of new atmospheric particles, Nature, 404, 66-69, 2000.

Kulmala, M., Dal Maso, M., Mäkelä, J. M., Pirjola, L., Väkevä, M., Aalto, P., Miikkulainen, P., Hämeri, K., and O’Dowd, C. D.: On the formation, growth and composition of nucleation mode particles, Tellus, 53B, 479-490, 2001 a.

Kulmala, M., Hämeri, K., Aalto, P. P., Mäkela, J. M., Pirjola, L., Nilsson, E. D., Buzorius, G., Rannik, Ü., Dal Maso, M., Seidl, W., Hoffman, T., Janson, R., Hansson, H.-C., Viisanen, Y., Laaksonen, A., and O'Dowd, C. D.: Overview of the international project on biogenic aerosol formation in the boreal forest (BIOFOR), Tellus, 53B, 324-343, 2001b.

Kulmala, M., Kerminen, V.-M., Anttila, T., Laaksonen, A., and O'Dowd, C. D.: Organic aerosol formation via sulphate cluster activation, J. Geophys. Res., 109, 4205, doi:10.1029/2003JD003961, 2004a.

Kulmala, M., Laakso, L., Lehtinen, K. E. J., Riipinen, I., Dal Maso, M., Anttila, T., Kerminen, V.-M., Hõrrak, U., Vana, M., and Tammet, H.: Initial steps of aerosol growth, Atmos. Chem. Phys., 4, 2553-2560, 2004b.

Kulmala, M., Vehkamäki, H., Petäjä, T., Dal Maso, M., Lauri, A., Kerminen, V.-M., Birmili, W., and McMurry, P. H.: Formation and growth rates of ultrafine atmospheric particles: A review of observations, J. Aerosol Sci., 35, 143-176, 2004c.
Kulmala, M., Lehtinen, K. E. J., and Laaksonen, A.: Cluster activation theory as an explanation of the linear dependence between formation rate of $3 \mathrm{~nm}$ particles and sulphuric acid concentration, Atmos. Chem. Phys., 6, 787-793, 2006, http://www.atmos-chem-phys.net/6/787/2006/.

Laakso, L., Petäjä, T., Lehtinen, K., Kulmala, M., Paatero, J., Hõrrak, U., Tammet, H., and Joutsensaari, J.: Ion production rate in a boreal forest based on ion, particle and radiation measurements, Atmos. Chem. Phys., 4, 1933-1943, 2004, http://www.atmos-chem-phys.net/4/1933/2004/.

Lauros, J., Nilsson, E. D., Vehkamäki, H., and Kulmala, M.: Atmospheric variability and binary homogeneous nucleation: A parametrisation and conditions required for a significant effect, Atmos. Res., 82, 503-513, 2006.

Mikkonen, S., Lehtinen, K., Hamed, A., Joutsensaari, J., Facchini, M., and Laaksonen, A.: Using discriminant analysis as a nucleation event classification method, Atmos. Chem. Phys., 6, 55495557, 2006, http://www.atmos-chem-phys.net/6/5549/2006/.

Nilsson, E. D. and Kulmala, M.: The potential for atmospheric mixing processes to enhance the binary nucleation rate, J. Geophys. Res., 103, 1381-1389, 1998.

Nilsson, E. D., Paatero, J., and Boy, M.: Effects of air masses and synoptic weather on aerosol formation in the continental boundary layer, Tellus, 53B, 462-478, 2001a.

Nilsson, E. D., Rannik, Ü., Kulmala, M., Buzorius, G., and O'Dowd, C. D.: Effects of continental boundary layer evolution, convection, turbulence and entrainment, on aerosol formation, Tellus, 53B, 441-461, 2001b.

Nilsson, E. D. and Kulmala, M.: Aerosol formation over the Boreal forest in Hyytiälä, Finland: Monthly frequency and annual cycles - the roles of air mass characteristics and synoptic scale meteorology, Atmos. Chem. Phys. Discuss., 6, 10 425-10 462, 2006.

Strader, R., Lurmann, F., and Pandis, S. N.: Evaluation of secondary organic aerosol formation in winter, Atmos. Environ., 33, 48494863, 1999.

Stull, R. B.: An introduction to boundary layer meteorology, Kluwer Academic Publishers, 1988.

Vesala, T., Haataja, J., Aalto, P., Altimir, N., Buzorius, G., Garam, E., Hämeri, K., Ilvesniemi, H., Jokinen, V., Keronen, P., Lahti, T., Markkanen, T., Mäkelä, J. M., Nikinmaa, E., Palmroth, S., Palva, L., Pohja, T., Pumpanen, J., Rannik, Ü., Siivola, E., Ylitalo, H., Hari, P., and Kulmala, M.: Long-term field measurements of atmospheresurface interactions in boreal forest combining forest ecology, micrometeorology, aerosol physics and atmospheric chemistry, Trends in Heat, Mass, Momentum Transfer, 4, 17-35, 1998.

Young, G. S.: Turbulence structure of the convective boundary layer II: PHOENIX 78 aircraft observations of thermals and their environment, J. Atmos. Sci., 45, 727-735, 1988. 